\title{
How work hours affect medical resident performance and wellness
}

Cite as: CMAJ 2019 September 30/191:E1086-7. doi: 10.1503/cmaj.1095798

Posted on cmajnews.com on Sept. 11, 2019

D oes spending less time in hospital mean medical residents are less prepared to practise medicine? This has been a topic of debate since 2003, when the Accreditation Council for Graduate Medical Education limited resident work hours in the United States to a maximum of 80 hours weekly. The same reform forbade individual shift lengths from exceeding 30 hours.

"You have very senior physicians who are still concerned that residents training today aren't as well prepared as they used to be," said Dr. Anupam Jena, a professor of health care policy and medicine at Harvard Medical School. Jena is the lead author of a recent study published in the $B M J$ evaluating the impact of resident work hours on long-term quality of care.

The study examined whether 30-day mortality, 30-day readmissions and inpatient spending varied depending on whether physicians were exposed to resident work-hour reforms. Using a random sample of patient records from the United States Medicare database, Jena and coauthors analyzed more than 450000 hospitalizations between 2000 and 2012 .

The researchers did not find any major differences in patient outcomes between internists in their first year of practice who were exposed to reforms and those trained before reforms came into effect. Jena said the duty-hour reforms were introduced primarily because of concerns for the safety of patients cared for by fatigued physicians. Still, he wasn't surprised to see little variation in performance between the two groups. The difference between 80 hours and the 100 hours per week that residents could have worked before the

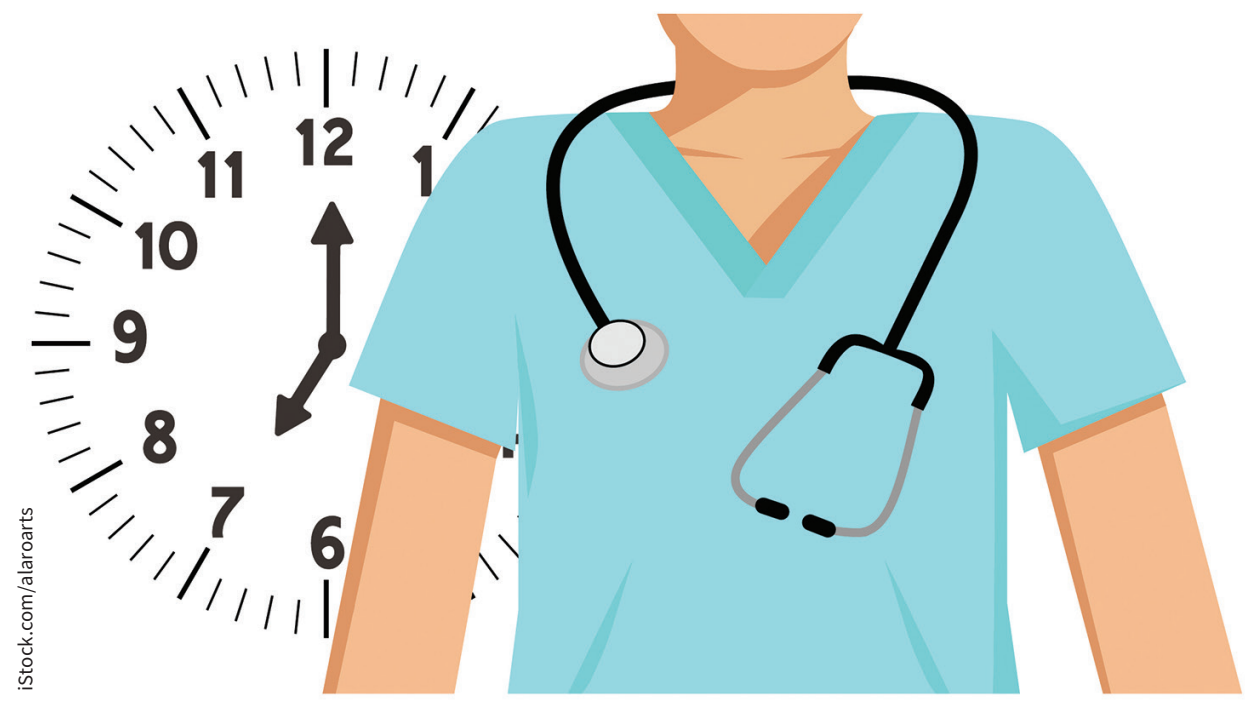

The decades-long debate over resident duty hours shows no signs of slowing.

reforms is unlikely to make much of a change in learning, either positive or negative, he said.

Dr. Kevin Imrie, physician-in-chief at the Sunnybrook Health Sciences Centre and cochair of the Fatigue Risk Management Taskforce, said the new study contributed an important finding, but like Jena, he wasn't surprised by the results. That's partly because of the difficulty in showing that any educational reform has an impact on patient outcomes years later.

But even if work hours don't seem to influence patient outcomes, they might be worth limiting for the sake of resident wellness, according to Dr. Emily Stewart, president of Resident Doctors of Canada. "Residents are both learners and frontline care providers, so you have the pressures of both impending exams but also these lengthy consecutive hours," said Stewart.
According to the organization's 2018 National Resident Survey, only $34.2 \%$ of residents reported that their work schedules left time for personal lives. The majority of residents worked 60 or more hours per week, and almost one in five worked 80 or more hours. What's more, $51.9 \%$ of residents reported experiencing symptoms of burnout.

Imrie agrees that resident wellness is an important outcome measure in and of itself. “Just because something doesn't improve patient outcomes doesn't mean it might not be worth doing for other reasons," he said. However, he added, improving resident wellness requires a more nuanced approach than simply reducing work hours.

In surgical specialties, specifically, reducing hours may not actually improve wellness. A systematic review led by Dr. Najma Ahmed, vice-chair of education 
of the University of Toronto's department of surgery, showed that although wellness among surgical residents did improve after the 80-hour work week was implemented, 16-hour duty maximums had little or negative effects on wellness. "Further erosion of training time should be considered with great caution," the authors concluded.

For Ahmed, it is not counterintuitive that shorter hours can lead to unhappiness among some trainees. "They want to be really good surgeons," she said. "When they have to excuse themselves from the [operating room] in the middle of a case, they feel like they didn't get what they needed to get out of it."

In 2013, the National Steering Committee on Resident Duty Hours, which Imrie cochaired and for which Ahmed was a consultant, recommended that efforts to reduce fatigue and improve patient safety should not focus on duty hours alone. Instead, according to Imrie, residency training programs should create riskmanagement plans and implement strategies to minimize fatigue. Residents could also be trained to understand fatigue and its effects better.

"It's not as if fatigue is this thing that you can avoid and never be exposed to," said Imrie. "It's something that touches all of us, and we need to figure out how to manage and mitigate it."

Caroline Mercer, Toronto, Ont. 